\title{
An Integrated Flood Risk Assessment and Mitigation Framework: Middle Cedar River Basin Case Study
}

\author{
Enes Yildirim ${ }^{1}$, Ibrahim Demir ${ }^{1}$ \\ ${ }^{1}$ Department of Civil and Environmental Engineering, University of Iowa, Iowa City, IA, USA \\ Corresponding Author: Enes Yildirim, enes-yildirim@uiowa.edu
}

\begin{abstract}
Property buyout is one of the most frequently preferred flood mitigation applications by decisionmakers for long-term risk reduction. Due to its high-level funding requirements as a mitigation solution, it requires extensive benefits and costs analysis for the selected region. Many communities in the State of Iowa experienced flood events (i.e. 1993, 2008, 2014, 2019) which resulted in a heavy economic impact over a couple of decades. Nearly 3,000 property acquisitions have been made between 2007 and 2017 by Iowa Homeland Security and Emergency Management Department (IHSEMD). This study presents a web-based Flood Risk Assessment and Mitigation Environment (FRAME) which provides visual data analytics capabilities to analyze property and community level benefit-cost analysis for property acquisitions. The FRAME allows users to query previous mitigation projects and buyouts that are completed by IHSEMD. A detailed benefit-cost analysis of historical property buyouts and direct losses of existing properties in the Middle Cedar watershed in Iowa is studied using stream gauge data from the United States Geological Survey (USGS). Projected stream gauge datasets which are outputs of two climate scenarios (A1FI-fossil intensive and A2-low emission) are also utilized to assess future avoided losses for acquisitions and possible direct economic losses for existing parcels. Case study results indicate that the average benefit-cost ratio (BCR) for most buyouts in Iowa is around 0.86 . In addition, nearly half of the buyouts reached to $4.72 \mathrm{BCR}$ in low emission and 6.3 BCR in fossil intensive climate projections.
\end{abstract}

Keywords: flood risk assessment, flood mitigation, property buyout, data analytics, web framework

This manuscript is an EarthArXiv preprint and has been submitted for possible publication in a peer reviewed journal. Please note that this has not been peer-reviewed before and is currently undergoing peer review for the first time. Subsequent versions of this manuscript may have slightly different content. If accepted, the final version of this manuscript will be available via the 'Peer-reviewed publication DOI' link on this webpage. Please feel free to contact the authors; we welcome feedback 


\section{Introduction}

In the United States, flooding had devastating impacts on communities in terms of social and economic aspects over the last couple of decades. Insured flood losses alone reached nearly $\$ 11$ billion dollars between 1999 and 2009 in the country (Highfield and Brody, 2012). Every year, state and local authorities apply to federal disaster aid programs for recovery and relief efforts after presidential disaster declarations. Flooding has the greatest proportion of the presidential disaster declarations (Downton and Pielke, 2001) accounting for over 45 percent. Nearly $\$ 80$ billion have been allocated over the past 15 years for disaster-related expenses, most of which are mainly caused by flooding in the United States (FEMA, 2020). Based on the climate projections, several studies reveal that mean annual streamflow values are projected to increase in many watersheds of the United States (Wang and Hejazi, 2011; Wuebbles and Hayhoe, 2004; Mallakpour and Villarini, 2015). Therefore, flood damage mitigation activities will remain critical for these watersheds to avoid future losses (Weber et al., 2018).

Flood damage mitigation applications can be classified into two main groups namely, structural and nonstructural measures. Structural measures focus on reducing the impact of flooding on communities by building levees, floodwalls, and improving drainage systems. On the other hand, non-structural measures like land-use control, acquisition, relocation, and early flood warning systems are preventive actions (Andjelkovic, 2001; Egli, 2002; Thampapillai and Musgrave, 1985). While prioritizing levee repairs can be a cost-effective solution to mitigate flood loss (Meunier and Merwade, 2014) as a structural measure for flood mitigation, large-scale buyouts could be a feasible solution as a non-structural flood mitigation strategy for private properties (Remo et al., 2011).

Benefit transfer is another common approach for an area to designate best practices for flood mitigation. Desvousges et al. define benefit transfer as scaling existing benefit estimations from an old study to a new study site (Desvousges et al., 1992; Boyle and Bergstrom, 1992). Even though some studies support benefit transfer as a way of assessing flood mitigation practices, they also highlight issues such as overestimation or underestimation of benefits which may lead to the failure of a mitigation effort (Brookshire and Neil, 1992; Ready and Navruz, 2006). Benefit transfer may not be successful in the context of assessing flood mitigation on properties due to the unique features of sites (land use, geography, building type, etc.) Therefore, site-specific and detailed investigations are essential for assessing flood mitigation on properties for selecting best practices.

Urbanization on floodplain results rises in property value therefore increase in possible flood damage (Roy et al., 2003). Because flood damage is inevitable in floodplains, settling, and accumulating values in the floodplain contributes to a higher risk of flood damage (Kreibich et al., 2002). Thus, long term flood mitigation strategy may be possible by removing structures that are in the higher risk flood zones. Although people who live near major waterways can be 
persuaded to participate in property buyout programs, the cost of the buyouts is another challenge to apply the solution (Knobloch, 2005). Property buyout is one of the most common practices to mitigate flooding impact in communities. One of the advantages of property buyout is creating permanent flood mitigation by removing a structure which is located in flood-prone areas. Existing property buyouts should be investigated in order to promote or demote the housing recovery policy. The housing recovery has not been examined in detail and is a relatively new subject for policy domains (Greer and Binder, 2017). In the United States, voluntary property buyout is supported by several federal grants such as the Hazard Mitigation Grant Program and Flood Mitigation Assistance Program. The main goal of these programs is to mitigate future hazards in communities by implementing long-term disaster mitigation measures (FEMA, 2020).

In the buyout process, the property is sold by the owner to the government through the political process which involves local, state, and federal participation (Marino, 2018). Depending on the grant program, the property must meet certain criteria to become eligible for the grant. For instance, the location of the property must be in a 100-year flood zone or a benefit-cost ratio (BCR) for the property to be cost-effective to proceed with the buyout (FEMA, 2013). Therefore, benefit-cost analysis (BCA) must be accurate as much as possible. The extensive flooding impact assessment should aim to cover the direct and indirect economic consequences of the flooding (Sieg et al., 2019). However, quantifying indirect flood losses is a great challenge due to uncertainties of the phenomena such its long term effects (Merz et al., 2011), data confidentiality (Andre et al., 2013), and its impact on the outer flood-prone area (Merz et al., 2010). Alternatively, comprehensive direct damage estimations can be considered for mapping the vulnerability of the communities (Moel et al., 2015). At this point, detailed direct flood vulnerability analysis becomes crucial input for the decision-making process to understand flooding impact for communities.

\subsection{Benefit Cost Analysis of Buyouts}

The majority of the studies are considered annualized flood losses to estimate BCA in their study sites. Although the statistical approach is one way to estimate possible losses, flooding may occur more frequently or less frequently due to climate change. Therefore, annualized flood loss estimations may mislead the results for BCA in study sites. To close this gap, historical stream gauges that are widely deployed in many regions in the United States can be utilized to assess avoided or existing losses for the properties. Historical gauge records can be processed to reveal peak flows over time in the study site. Then, avoided or existing flood losses are estimated using flood maps that are corresponded to the peak flows. This approach is also applicable to the output of short-term flood forecasting (Sit and Demir, 2019; Xiang et al., 2020) and long-term climate projections studies that allow estimations for potential future damages. Based on climate projection studies, different precipitation scenarios and streamflow estimates can be generated for mitigation analysis. Thus, BCA for a property can be investigated by evaluating multiple climate projections such as extreme, moderate, and optimistic precipitation scenarios. 
Delivery of the BCA analysis may be improved by using web frameworks which can allow decision-makers access and evaluate their area of responsibilities. Web frameworks allow assessing property losses (Yildirim, 2017) and evaluating areas with different geographic scales, and reduce effort, time, and resource requirements for the decision-makers. Decision support systems (Xu et al., 2020) can be enabled via web applications (Carson et al., 2018) with data analytics capabilities to evaluate what-if scenarios and analysis in one environment (Demir et al., 2018). Moreover, public participation (Sermet et al., 2020) and understanding of BCA and mitigation decisions can be improved with easy to use web interfaces to encourage voluntary property buyouts.

\subsection{Proposed Framework}

Web-based systems are becoming increasingly popular both for research and operational applications in water resources and hydrology (Demir and Beck, 2009). Management and analysis of large-scale datasets on the web requires optimized data structures (Demir and Szczepanek, 2017; Sit et al., 2019), crowdsourced data collection efforts (Sermet et al., 2020), and distributed computing frameworks (Agliamzanov et al., 2020). The latest web standards (i.e. WebXR, Speech Recognition API) augments decision support systems with ontologies (Sermet and Demir, 2019b) and virtual reality (Sermet and Demir, 2019a) to communicate information and model results.

In this study, a generalized web-based Flood Risk Assessment and Mitigation Environment (FRAME) is developed to provide visual data analytics capabilities to analyze property and community level benefit-cost analysis for property acquisitions. The FRAME includes historical mitigation projects and property acquisitions that are completed by IHSEMD after 2008 and 2014 flood events. The developed framework allows historical and future flood damage assessment on existing buildings and historical property buyouts in the Middle Cedar watershed. One of the objectives of this study is to provide a real-time data analytics and decision support framework to help mitigation decisions by streamlining risk and mitigation analysis, reducing the learning curve and increasing accessibility of analysis results for decision-makers and public. The outcomes of the study include a data analytics framework for historical mitigation projects and property acquisition in multiple geospatial scales, providing historical benefit and damage estimation for property acquisitions by using historical gauge data and flood event identification, and analyzing future BCA based on climate forecasts ( 2 scenarios) for next 30 years.

The remaining sections of the paper follow by methodology and procedures for the BCA, damage analysis for historical and future scenarios, and development of a web-based framework. Following, results are shared along with the detailed case study for the Middle Cedar watershed. The data analytics framework, mitigation efforts in the state, and statewide analysis are discussed. In the end, the conclusion of the study and prospective studies are provided. 


\section{Flood Risk Assessment and Mitigation Framework}

The web-based framework is designed to allow users to query and evaluate historical mitigation projects and property acquisitions in the State of Iowa. The generalized structure of the framework allows the easy adaption of the system in other regions. There are 3 main layers within the framework: data management layer, data analytics layer, and mapping and visualization layer. Each layer is explained in the following subsections. The structure for the framework is illustrated in Figure 1. Briefly, datasets are stored, manipulated, and prepared in the data management layer and integrated into the data analytics layer. The data analytics layer processes the datasets and provides the outputs of the analysis to the mapping and visualization layer. At last, the visualization and mapping layer delivers the information to the client-side user interface.

\subsection{Data Management Layer}

The framework utilizes various datasets such as historical mitigation projects and acquisitions, United States Geological Survey (USGS) stream gauge data, streamflow estimations based on climate scenarios, county tax assessor property dataset, flood inundation maps, damage curves, and satellite imagery data. Historical mitigation projects contain information about federal grants that are distributed at the county and city level. Property acquisition data stores acquisition cost, date, and eligible grant type in county, city, and property level. The county tax assessor property dataset is integrated into the system for supporting future property buyout decisions. USGS stream gauge data is collected in each community to classify historical flood events. The classification is also applied to streamflow projection datasets to list projected flood events.
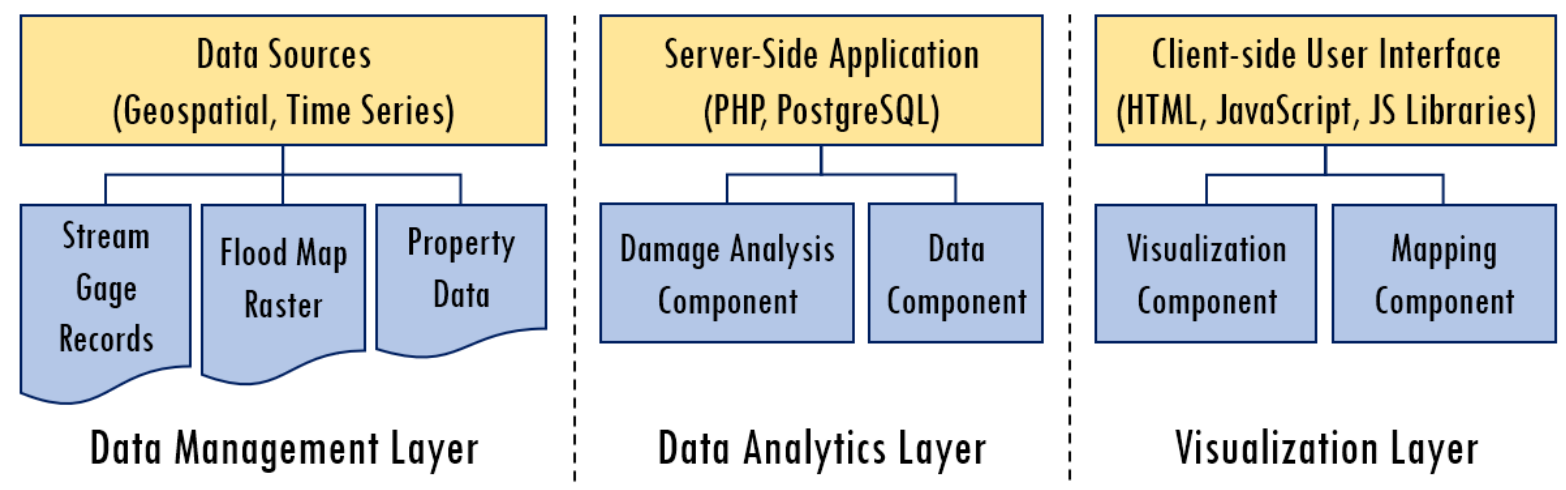

Figure 1. Cyberinfrastructure system for the web-based framework

Damage Curves: Damage curves which are developed by the United States Army Corps of Engineers (USACE) are employed in the framework. In Figure 2, 6 out of the 36 widely used damage curves are shared for residential and commercial properties. Briefly, damage curves provide the relation between flood depth and damage percentage for certain occupancy types (Yildirim \& Demir, 2019). Each specific occupancy type has separate structural and content damage curves. 

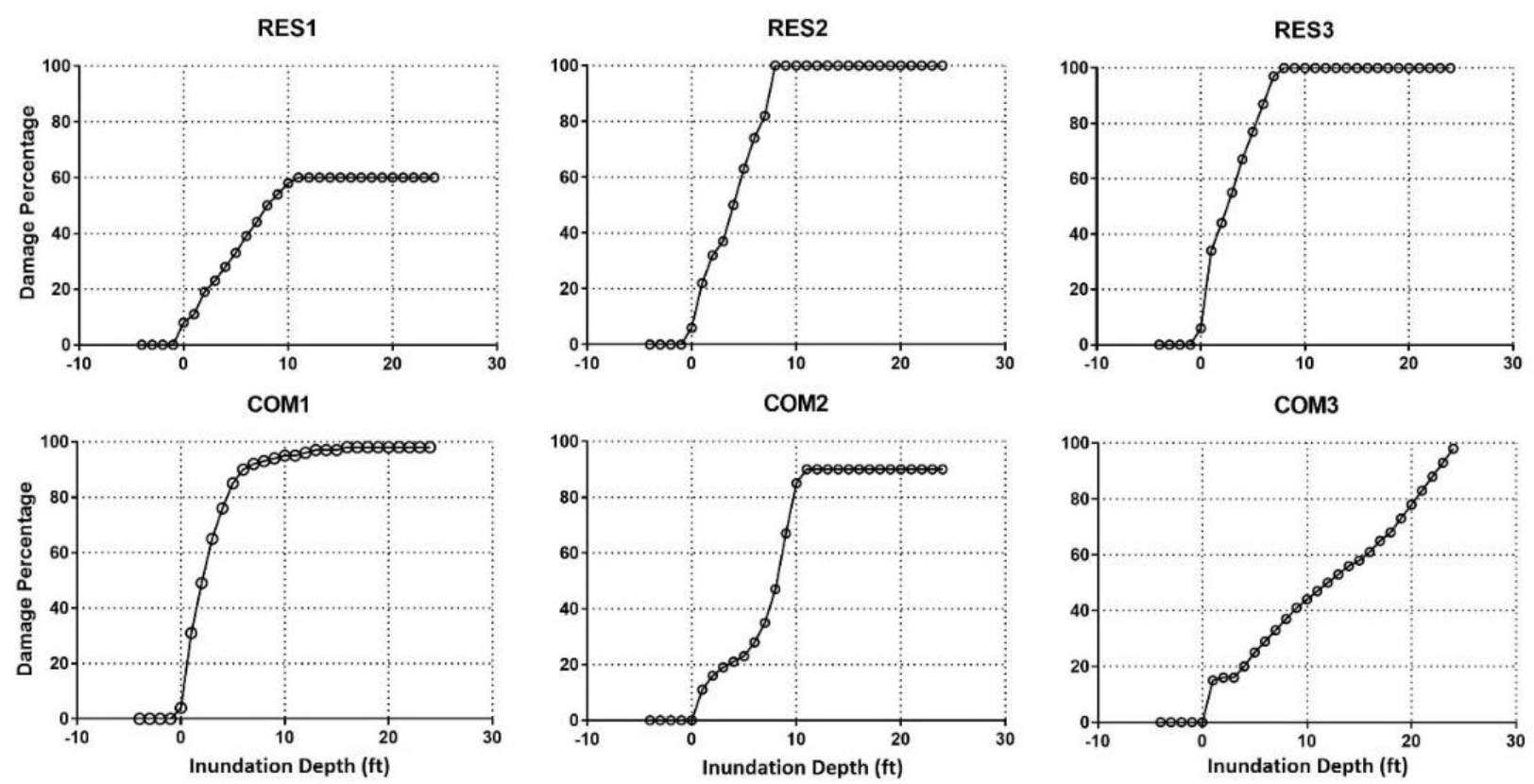

Figure 2. Flood inundation depth-damage (structural) relation functions (Yildirim \& Demir, 2019)

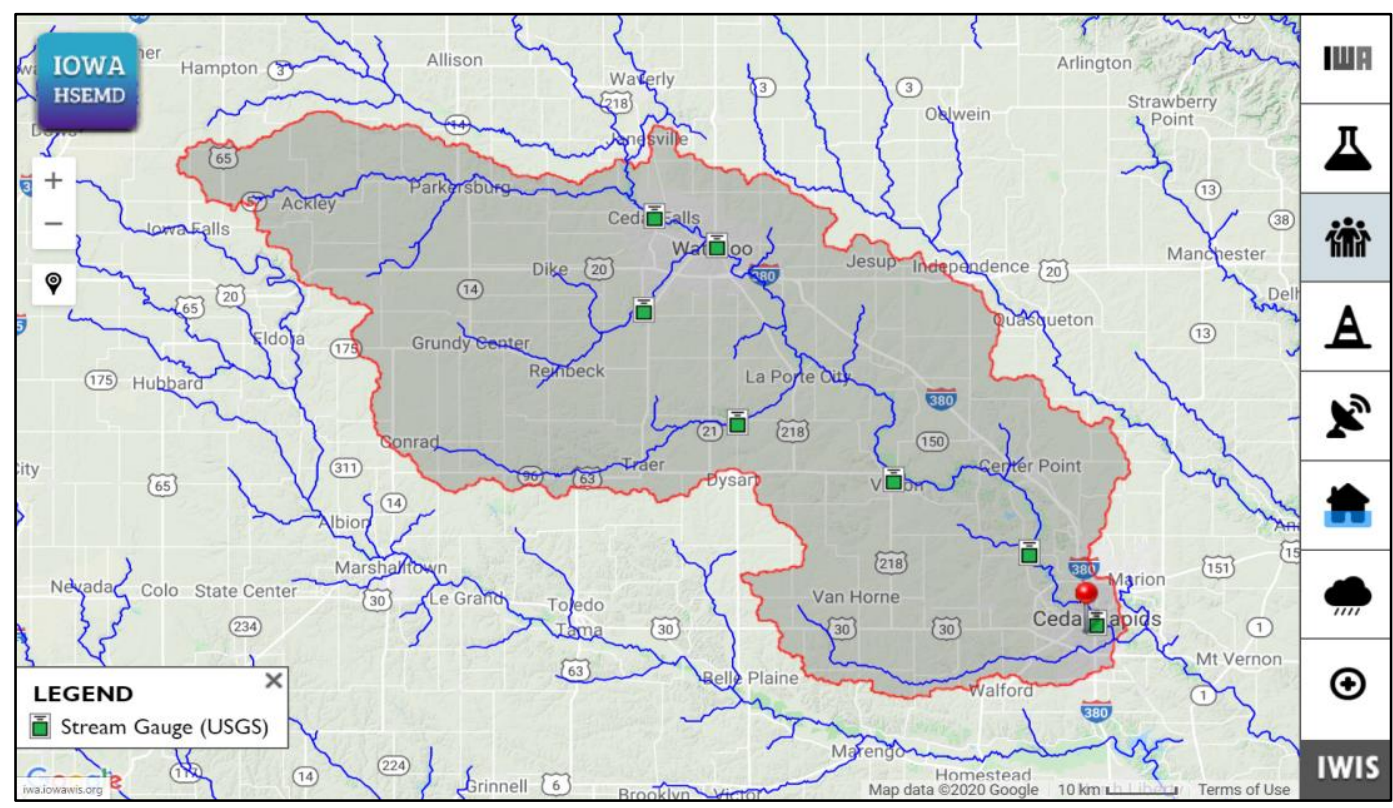

Figure 3. USGS gauges locations in the Middle Cedar watershed

Gauge Records: Historical USGS stream gauge datasets from 2009 to 2019 and streamflow projections based on climate models are analyzed to classify flooding events. The gauge records are collected for 7 different locations for the selected communities (Figure 3). Streamflow projections are generated for these gauge sites based on 19 climate projections (Quintero et al., 2018). In this study, the projected streamflow values between 2020 and 2050 from the CCSM3 (Community Climate System Model) model and A1FI and A2 climate scenarios are used. While 
the A1FI scenario is generated based on fossil intensive activities, the A2 scenario is generated based on low emissions (IPCC, 2000). The details about the climate model and streamflow projections are available in Quintero et al., 2018. Although multiple peak flows are possible to observe in a short period of time from a hydrological point of view, the highest peak flow is considered to estimate flood loss due to the long flood recovery process which allows us to prevent overestimation of the loss. Therefore, the algorithm filters the peak flows that fall in the 6 months range and classify the highest observed peak as the main flood event.

Parcel Information: Property information is collected from 2 different sources including county tax assessor parcel data and IHSEMD acquired property data. Geolocation of the existing parcels is crossed-checked by using Google Maps satellite imagery. To validate the location of property buyouts, historical Google Maps satellite imagery maps are used. Following, damage curve ids are connected using occupancy types to estimate flood damage. Flood depths for individual buildings are estimated using flood inundation maps by extracting foundation height for each building. Then, damage percentage, structural loss, and content losses are calculated for buildings.

Flood Maps: The flood maps for the Middle Cedar watershed are acquired from Iowa Flood Center. The flood maps correspond to several flood scenarios including 50-, 20-, 10-, 4-, 2-, 1-, 0.5-, and 0.2-percent-annual-chance flows (2-, 5-, 10-, 25-, 50-, 100-, 200-, and 500-year return period flows, respectively) by using high-resolution LiDAR digital elevation model data (Gilles et al., 2012).

Mitigation Project Records: Historical mitigation project datasets are created by IHSEMD stored in a relational database (i.e. PostgreSQL) in the framework within Projects, Project Applicants, and Allocated Grants data tables. A relational data schema is created based on unique grant ids, applicant ids, and project ids. Following, advanced queries to filter and extract information from the project records are integrated into the data analytics framework.

\subsection{Data Analytics Layer}

The data analytics layer primarily utilizes historical mitigation project records, property acquisitions, and estimated historical and avoided losses. The layer is developed using HTML, JavaScript, and various JS libraries. Datasets are handled in the PostgreSQL server which has the capability for storing, managing and querying geospatial data. Using a server-side scripting language (i.e. PHP: Hypertext Preprocessor), datasets are integrated to the client-side user interface by creating multiple scopes to query datasets such as location (state-wide, county, city, property level), time parameter, and program type. Damage assessment and benefit-cost analysis for existing and acquired properties are handled in the data analytics layer.

Damage Assessment: The methodology for the damage assessment is employed from the software called HAZUS-MH (Hazard United States; Scawthorn et al.) HAZUS tool is one of the most commonly used loss assessment software by decision-makers. However, it requires users to 
acquire and install various software such as ESRI ArcGIS, Spatial Analyst, and Microsoft SQL Server. The learning curve is also another challenge for its users to utilize the analyses. The damage assessment methodology is used from HAZUS and utilized in a real-time framework by taking advantage of web technologies to reduce the limitations and provide more capabilities to create an enhanced and integrated data analytics framework. Therefore, software limitations such as GIS (Geographic Information System), software licenses, and database requirements are eliminated. Besides, the accessibility of the analysis is enhanced and made available for not only decision-makers but also for the general public.

Benefit-Cost Analysis: BCA for buyouts requires 2 main inputs namely the cost of acquisition and cumulative avoided losses. For each property buyout, final acquisition cost and final acquisition date are recorded. Cumulative avoided losses are estimated for both structural and content damage. It is important to emphasize that cumulative losses only cover direct structural and content losses that occurred between the final acquisition date and 2019. The ratio of cumulative loss and acquisition cost gives the benefit-cost value for the property. If the ratio is equal or higher than 1, the acquisition can be accepted as successful. To summarize city level BCA, property level acquisition costs and cumulative losses are aggregated and presented at the city level. Climate scenario-based losses are estimated separately to reflect future avoided losses and BCA. Historical and future losses are estimated for both acquired and existing properties.

Limitations: In this study, avoided and future losses are investigated only from the direct flood loss perspective due to data limitations. Although estimating direct loss is significant, other items can be used to contribute BCA such as avoided loss of life and injuries, emergency expenses, avoided displacement costs, avoided rental income loss, socioeconomic recreational facilities as benefits and park construction and maintenance, and loss of property tax, as costs (White, 2011).

\subsection{Mapping and Visualization Layer}

The mapping and visualization layer receive query outputs from the data analytics layer and conveys results to the user interface and initializes Google Maps JavaScript API to visualize results. At the state-wide and county level, the results are visualized using a common color schema (from red to green) to illustrate variations. The interface allows results to be visualized by program type, data source, and time. In the city and property level, tables that deliver information about the applicant of the project, cost of the project, avoided losses, and historical losses are generated. The information panel provides a summary of the analysis for the selected city or property.

\section{Results and Discussions}

This section includes a summary of results generated by the data analytics framework for the State of Iowa and a detailed analysis of the Middle Cedar watershed case study. 


\subsection{Data Analytics Framework}

The data analytics system is developed to visualize historical mitigation projects and property acquisitions of IHSEMD for the State of Iowa between 2007 and 2017. The framework provides a data analytics panel to query by data source, program type, location, and time parameter. Table 1 shows the query scope for the data analytics framework which filters historical mitigation projects, project applicants and allocated grants based on the data source, program type, location scope, and data parameter.

Table 1. List of filter and query parameters in data analytics framework

\begin{tabular}{|l|l|l|l|}
\hline Data Source & Program Type & Location Scope & Data Parameter \\
\hline Projects & Hazard Mitigation & State-wide & Project Start Date \\
\hline Property Acquisitions & Individual Assistance & County Jurisdiction & Project Closeout Date \\
\hline Project Applicants & Public Assistance & City Boundary & Final Acquisition Date \\
\hline Allocated Grants & Pre-disaster Mitigation & Property Level & Historical Loss \\
\hline
\end{tabular}

As seen in Figures 4 and 5, property acquisition is a common application in Iowa to mitigate flooding impact. Nearly 3,000 property acquisitions have been made between 2007 and 2017. The majority of the property acquisitions were completed after the 2008 flooding event. The second-largest event for property acquisitions was made after 2014 flooding. Public assistance has the largest proportion of grants compared to Hazard Mitigation Assistance and Individual Assistance Grant programs. Most of the pre- and post-hazard mitigation projects are completed in eastern Iowa (Figure 6). The main reason is that eastern Iowa is highly urbanized and hosts large cities in Iowa such as Cedar Rapids, Waterloo, Iowa City, Cedar Falls, and Vinton. Overall, Linn County received the highest number of projects which is 1,285 of the 21,712 projects between 2007 and 2017 in the State of Iowa. Linn County is followed by Johnson, Black Hawk, Pottawattamie, and Polk counties in a number of projects. North-western Iowa has received the least number of projects compared to the other regions due to rare flood events.

The system provides mitigation analysis in multiple scales such as state-wide, county, city, and property level. In Figure 6, the city level summary panel is visualized for the City of Vinton. The city-level analysis summarizes the number of records, accounts, and applicants for mitigation grants, total eligible obligated, and federal obligated dollars for the city. The system also allows us to examine the total amount of acquisition cost, number of classified flooding events after the acquisition date, number of affected buildings, and total damage as an avoided loss. In addition, damage estimates for the existing buildings are also given to support future decisions for future property acquisitions or other mitigation activities. Overall, a general idea about mitigation grants, existing mitigation efforts, and future mitigation possibilities are provided in the interface to decision-makers. 


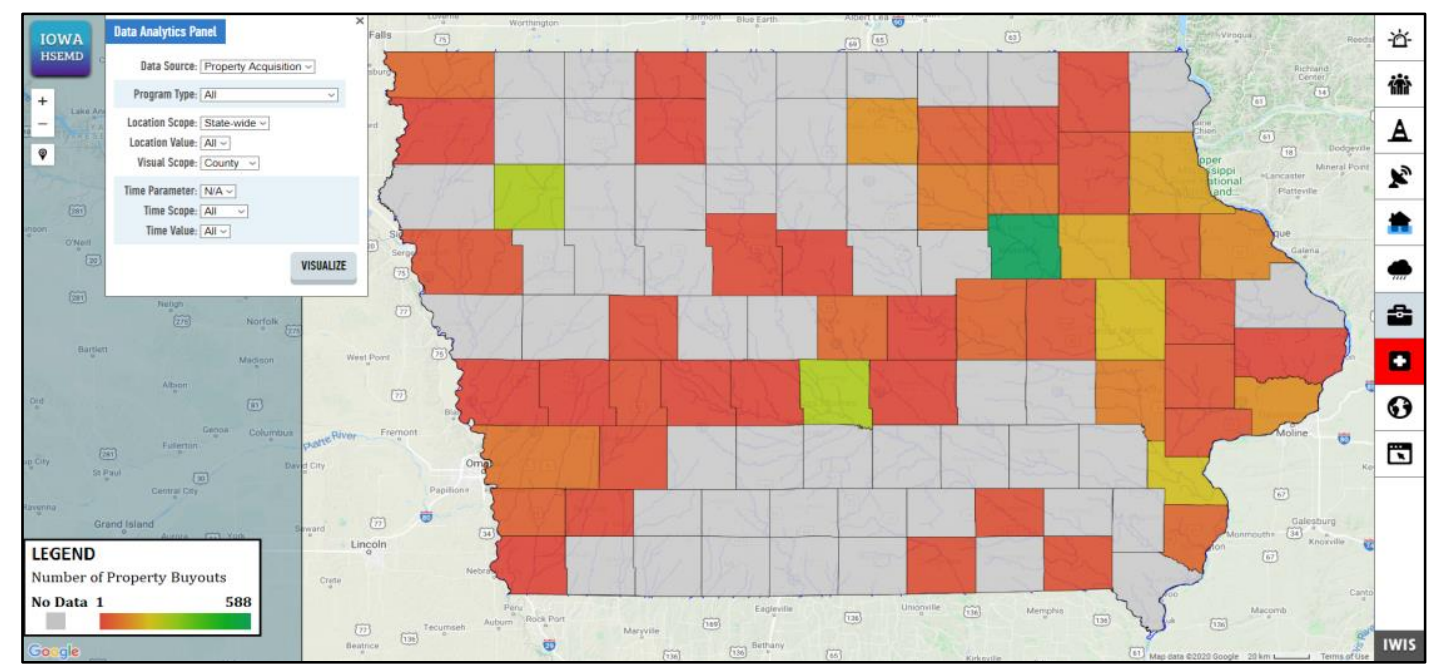

Figure 4. Distribution of property buyouts in the state of Iowa

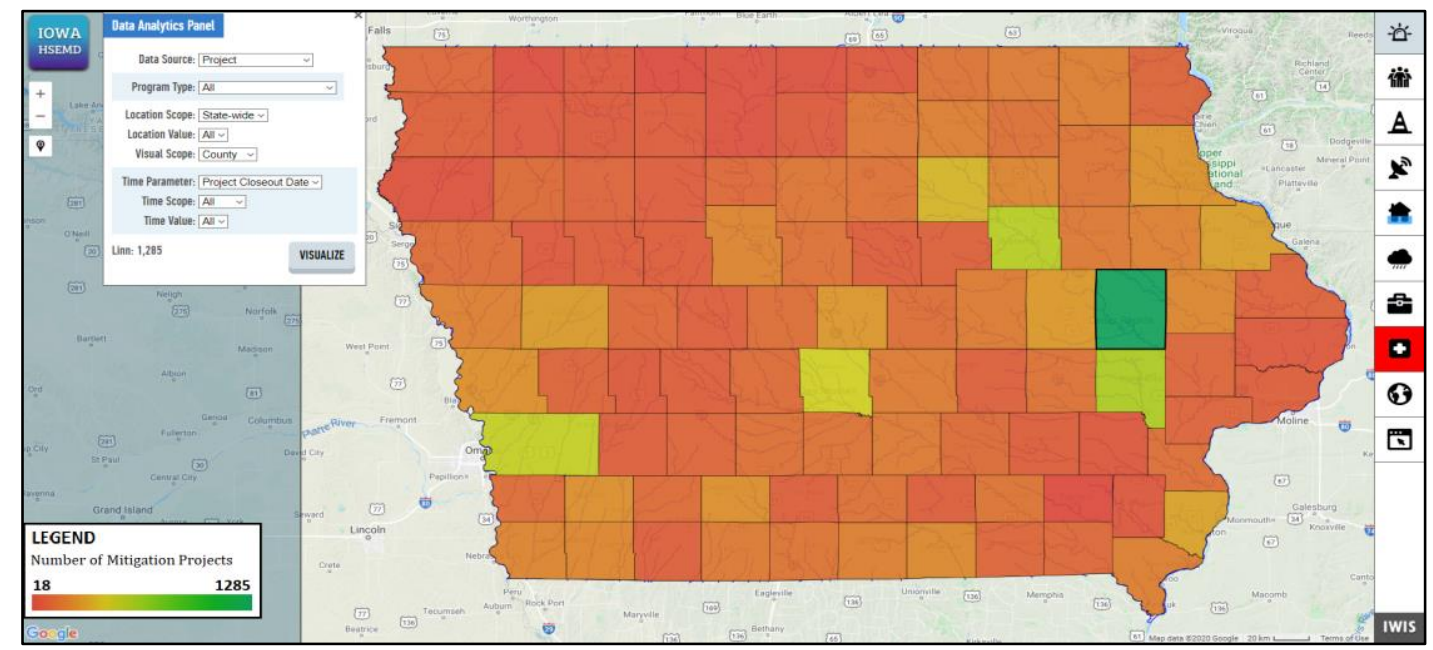

Figure 5. Distribution of post and pre-hazard mitigation projects

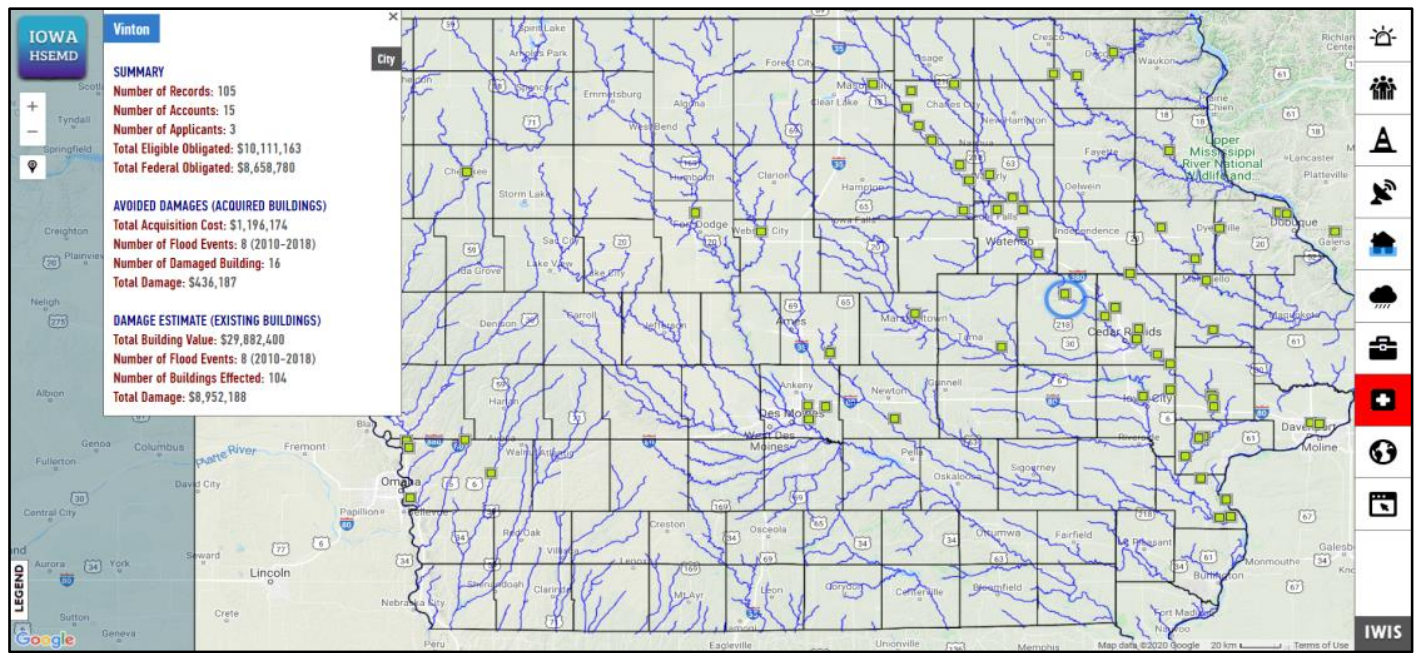

Figure 6. Mitigation projects and property acquisition summary for cities 
Figure 7 illustrates 20 counties in Iowa that had most disaster declarations over the last 65 years due to flooding events compared to their populations and the number of property acquisitions. Pre- and post-hazard mitigation activities are generally funded by federal aid so that federal disaster declaration is required to receive the aid. On the other hand, population density should be investigated to understand the distribution of the property buyouts in the state to understand the main driving factor behind the decisions for property acquisitions. We found that the number of disaster declarations and the population of the community does not show a strong correlation to property acquisitions. Because property acquisitions are made voluntarily, the public may be willing to participate based on the amount of damage on their property or the participation from their community. Willingness to participate in property buyout programs can be investigated further with additional research and surveys.
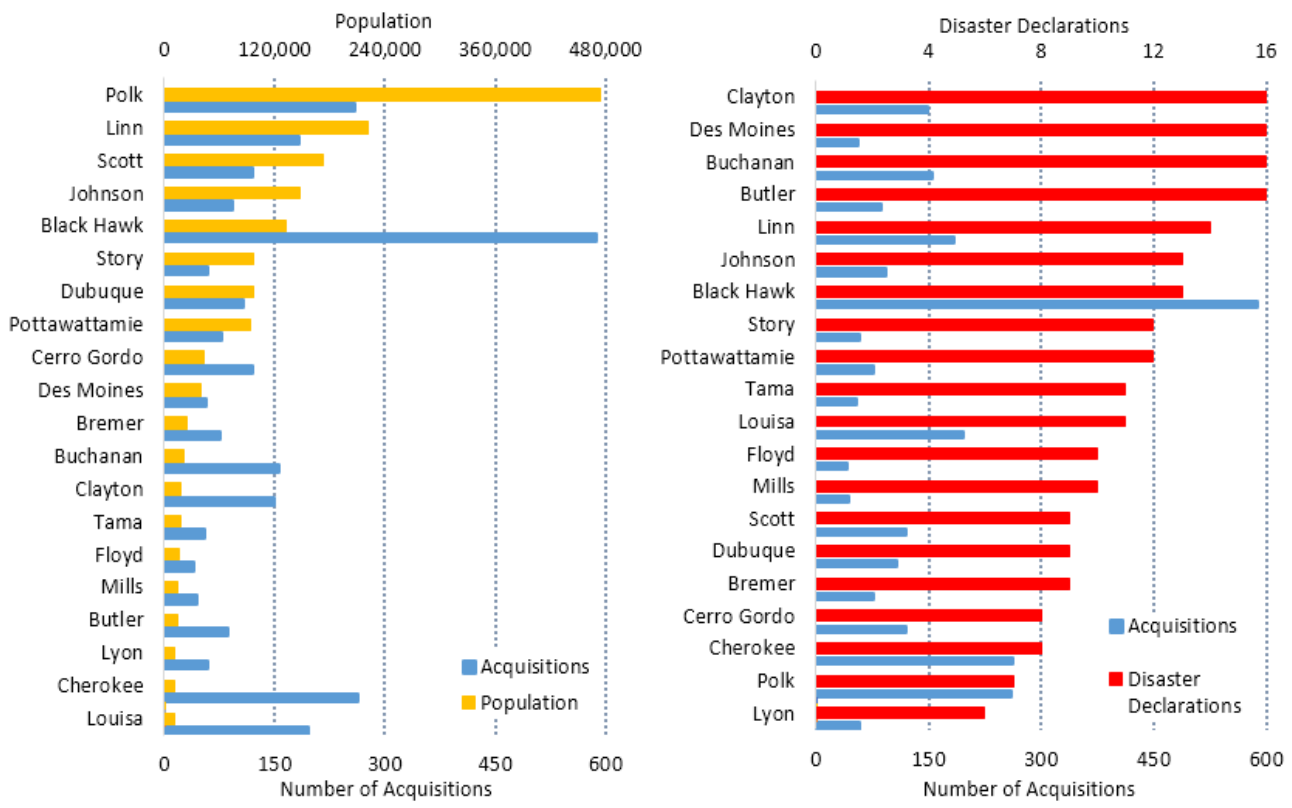

Figure 7. Project and acquisition analysis summary for cities

\subsection{Middle Cedar Watershed Case Study}

Middle Cedar watershed has experienced severe flooding events in history and has several large communities in the State of Iowa (Figure 8). The majority of the buyouts in the watershed are made in Cedar Falls, Cedar Rapids, and Waterloo. In this study, benefit-cost analysis is carried out for all properties in the Middle Cedar watershed. As shown in Figures 4 and 5, communities in the Middle Cedar watershed received relatively larger amounts of flood mitigation grants compared to other regions in Iowa. Therefore, Middle Cedar is selected to investigate benefitcost analysis for property acquisitions based on historical and projected flooding events. 282 property buyouts are analyzed in the Middle Cedar watershed between 2009 and 2017. Historical gauge records and streamflow projections from 2020 to 2050 are processed to identify flood events and their magnitude. Following, corresponding flood maps are used based on classified 
flood events to estimate historical and future flood losses in communities. In Figure 9, direct flood losses for historical and future flood events are generated for three major cities. Red columns represent the direct flood losses between 2009 to 2017. Blue and green columns represent future damage estimates as a combination of structural and content losses between 2020 and 2050.

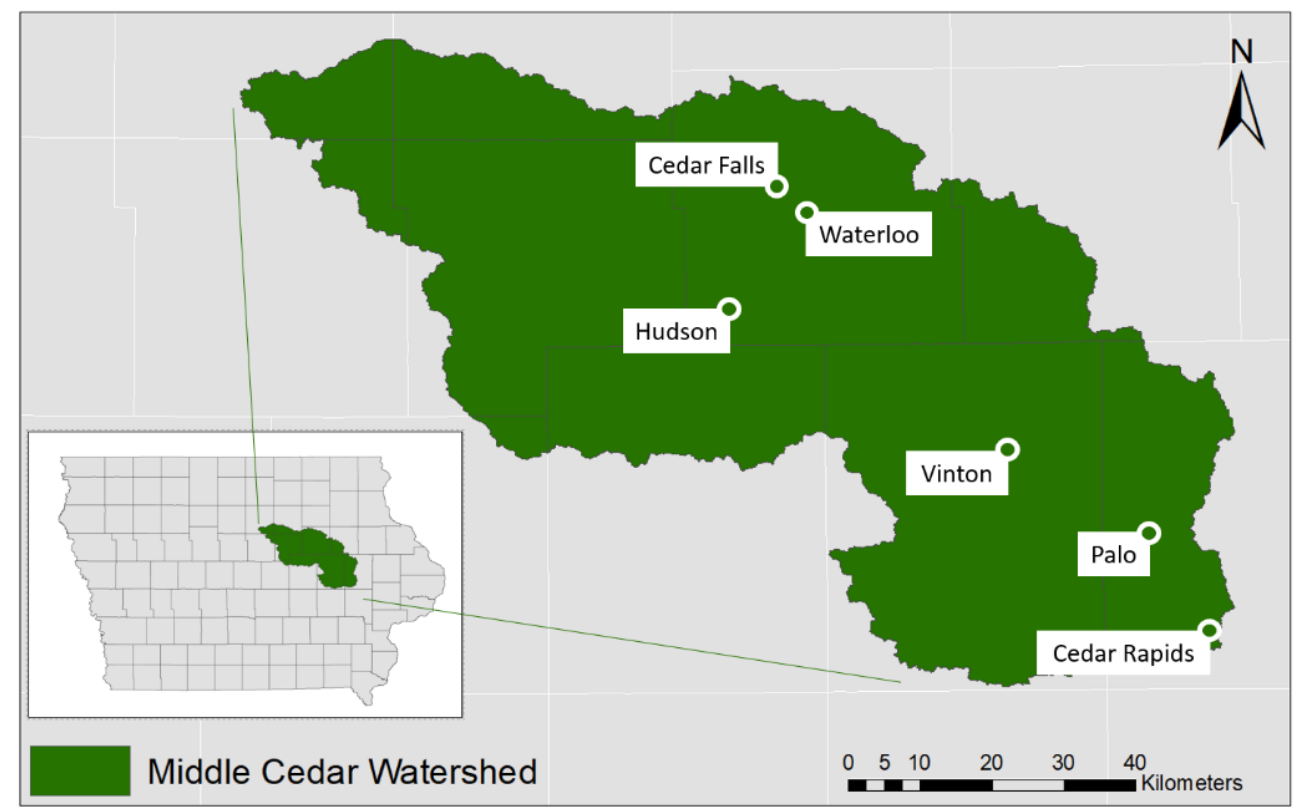

Figure 8. Middle Cedar watershed study area for benefit cost analysis

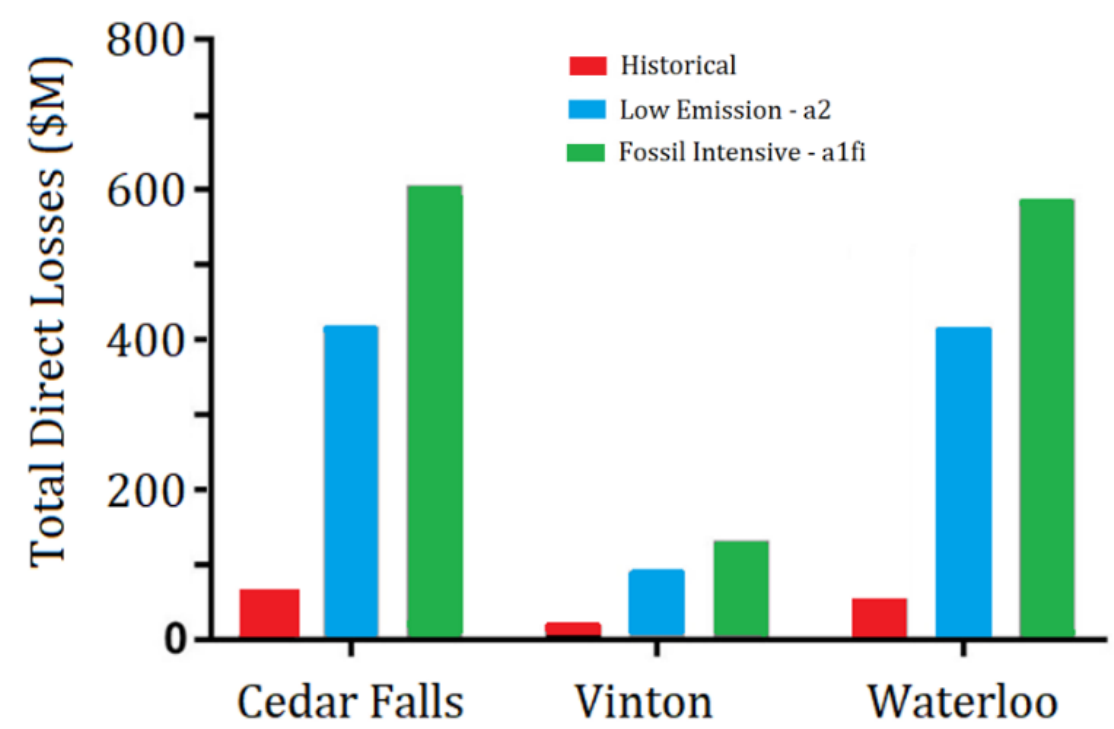

Figure 9. Avoided and projected total direct losses for major cities in Middle Cedar watershed

In Figure 10, direct loss per structure is presented for selected Middle Cedar communities. Waterloo shows the highest loss per structure. This is a strong indicator that the community has vulnerable industrial or commercial structures within the flood-prone zones. In the property 
dataset, commercial and industrial buildings are relatively more valuable compared to residential, governmental, and public buildings which are reflected in structural and content damage.

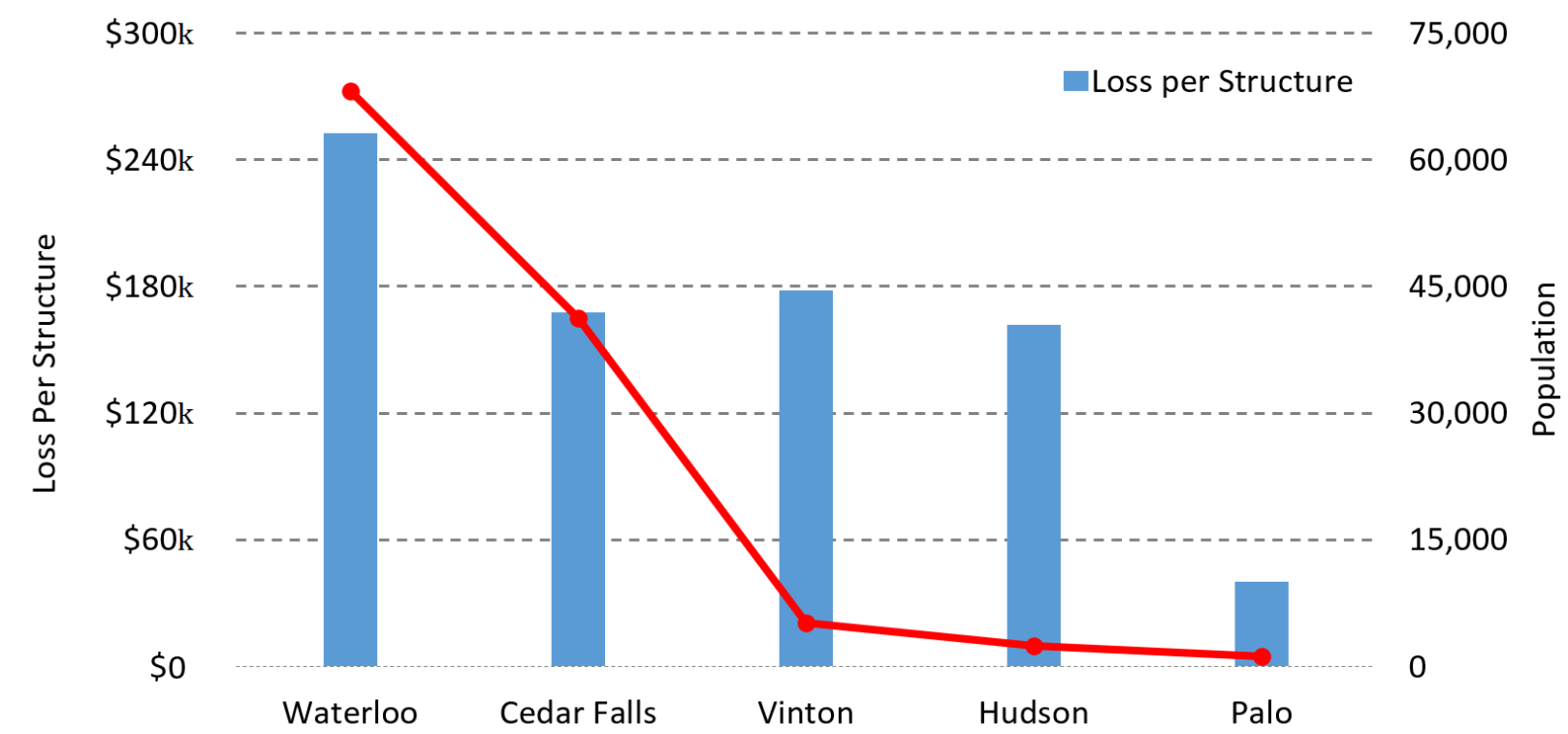

Figure 10. Direct losses per structure in Middle Cedar communities (2009 - 2017)

In Table 2, historical and projected avoided losses, number of properties, number of events, and community level BCAs are shared for the property buyouts in the Middle Cedar watershed. The city of Cedar Falls has the highest portion of analyzed property buyouts in this study. Between the acquisition date which is 2009 for most of the buyouts and 2019, nearly half of the analyzed buyouts are found to be successful. The community BCR for Cedar Falls is estimated as 0.86 by only considering direct losses. Considering projected streamflow values that are outputs of climate scenarios (a2 and a1fi), overall buyouts in the Middle Cedar watershed are estimated to be successful in both scenarios.

Table 2. Estimated avoided direct flood losses for major cities in Middle Cedar

\begin{tabular}{|c|c|c|c|c|c|c|c|c|c|c|c|c|c|}
\hline \multirow[b]{2}{*}{ County } & \multirow[b]{2}{*}{$\begin{array}{l}\text { Cost of Total } \\
\text { Acquisitions }\end{array}$} & \multicolumn{4}{|c|}{$\begin{array}{c}\text { Historical } \\
(2009-2017)\end{array}$} & \multicolumn{4}{|c|}{$\begin{array}{l}\text { Low Emission - a2 } \\
(2020-2050)\end{array}$} & \multicolumn{4}{|c|}{$\begin{array}{l}\text { Fossil Intensive - a1fi } \\
\quad(2020-2050)\end{array}$} \\
\hline & & $\begin{array}{l}\text { Avoided } \\
\text { Loss }\end{array}$ & Properties & Events & BCR & $\begin{array}{c}\text { Projected } \\
\text { Avoided Loss }\end{array}$ & Properties & Events & BCR & $\mid$\begin{tabular}{c|} 
Projected \\
Avoided Loss
\end{tabular} & Properties & Events & BCR \\
\hline Cedar Falls & $\$ 5.67 \mathrm{M}$ & $\$ 4.91 \mathrm{M}$ & 121 & 4 & 0.86 & $\$ 26.94 \mathrm{M}$ & 121 & 18 & 4.72 & $\$ 36.36 \mathrm{M}$ & 121 & 19 & 6.35 \\
\hline Cedar Rapids & $\$ 2.21 \mathrm{M}$ & $\$ 0.20 \mathrm{M}$ & 2 & 2 & 0.09 & $\$ 2.71 \mathrm{M}$ & 52 & 7 & 1.25 & $\$ 6.72 \mathrm{M}$ & 52 & 15 & 3.05 \\
\hline Palo & $\$ 0.77 \mathrm{M}$ & $\$ 0.11 \mathrm{M}$ & 6 & 5 & 0.14 & $\$ 0.90 \mathrm{M}$ & 15 & 19 & 1.17 & $\$ 1.37 \mathrm{M}$ & 15 & 19 & 1.75 \\
\hline \begin{tabular}{|l|} 
Vinton \\
\end{tabular} & $\$ 1.24 \mathrm{M}$ & $\$ 0.44 \mathrm{M}$ & 16 & 8 & 0.37 & $\$ 1.92 \mathrm{M}$ & 26 & 26 & 1.63 & $\$ 2.81 \mathrm{M}$ & 26 & 26 & 2.35 \\
\hline Waterloo & $\$ 3.94 \mathrm{M}$ & $\$ 1.13 \mathrm{M}$ & 44 & 5 & 0.29 & $\$ 14.53 \mathrm{M}$ & 50 & 14 & 3.72 & $\$ 20.34 \mathrm{M}$ & 50 & 19 & 5.22 \\
\hline
\end{tabular}

In Table 3, estimated direct losses for existing properties in Middle Cedar watershed is shared for historical events and future scenarios. Cedar Falls, Waterloo, and Vinton are found to be the most vulnerable between 2009 and 2019. Also, projected streamflow values are most likely to cause 
heavy losses in these communities. It can be concluded that future mitigation efforts may be needed for these communities.

Table 3. Estimated potential direct flood losses for major cities in Middle Cedar

\begin{tabular}{|c|c|c|c|c|c|c|c|c|c|c|}
\hline \multirow[b]{2}{*}{ County } & \multirow[b]{2}{*}{$\begin{array}{l}\text { Cost of Total } \\
\text { Acquisitions }\end{array}$} & \multicolumn{3}{|c|}{$\begin{array}{c}\text { Historical } \\
(2009-2017)\end{array}$} & \multicolumn{3}{|c|}{$\begin{array}{l}\text { Low Emission - a2 } \\
(2020-2050)\end{array}$} & \multicolumn{3}{|c|}{$\begin{array}{l}\text { Fossil Intensive - a1fi } \\
(2020-2050)\end{array}$} \\
\hline & & $\begin{array}{c}\text { Total Avoided } \\
\text { Loss }\end{array}$ & Properties & Events & $\begin{array}{c}\text { Projected } \\
\text { Avoided Loss }\end{array}$ & Properties & Events & \begin{tabular}{|c|} 
Projected \\
Avoided Loss
\end{tabular} & Properties & Events \\
\hline Cedar Falls & $\$ 487.38 \mathrm{M}$ & $\$ 69.31 \mathrm{M}$ & 414 & 6 & $\$ 417.61 \mathrm{M}$ & 554 & 28 & $\$ 605.81 \mathrm{M}$ & 555 & 26 \\
\hline Hudson & $\$ 30.15 \mathrm{M}$ & $\$ 1.92 \mathrm{M}$ & 12 & 5 & $\$ 5.99 \mathrm{M}$ & 12 & 19 & $\$ 8.47 \mathrm{M}$ & 52 & 20 \\
\hline \begin{tabular}{|l|} 
Palo \\
\end{tabular} & $\$ 70.04 \mathrm{M}$ & $\$ 0.69 \mathrm{M}$ & 17 & 5 & $\$ 0.13 \mathrm{M}$ & 136 & 14 & $\$ 23.03 \mathrm{M}$ & 136 & 19 \\
\hline Vinton & $\$ 84.97 \mathrm{M}$ & $\$ 18.33 \mathrm{M}$ & 103 & 7 & $\$ 91.44 \mathrm{M}$ & 140 & 26 & $\$ 132.09 \mathrm{M}$ & 140 & 26 \\
\hline Waterloo & $\$ 942.54 \mathrm{M}$ & $\$ 51.59 \mathrm{M}$ & 204 & 6 & $\$ 416.26 \mathrm{M}$ & 817 & 23 & $\$ 586.82 \mathrm{M}$ & 817 & 25 \\
\hline
\end{tabular}

One of the capabilities of the data analytics framework is generating analysis at the property level. In Figure 11, results and visualization of property level analysis from the framework are demonstrated. The system generates avoided and historical losses for acquired and existing properties respectively. Building value or acquisition cost, property-specific id, the applicant for the property acquisitions, and other related information are also provided in the information panel. This allows investigating the benefit-cost ratio for the historical buyout, and potential buyout decisions for an existing property in the communities. Acquired properties are illustrated with red markers and existing properties are shown with yellow markers. When the property is selected, the data analytics tool reveals historical floods that affected the property. Date of the events based on USGS gauges, return periods for flooding events, the estimated total of direct content and structural flood losses, and total loss over the years are given.

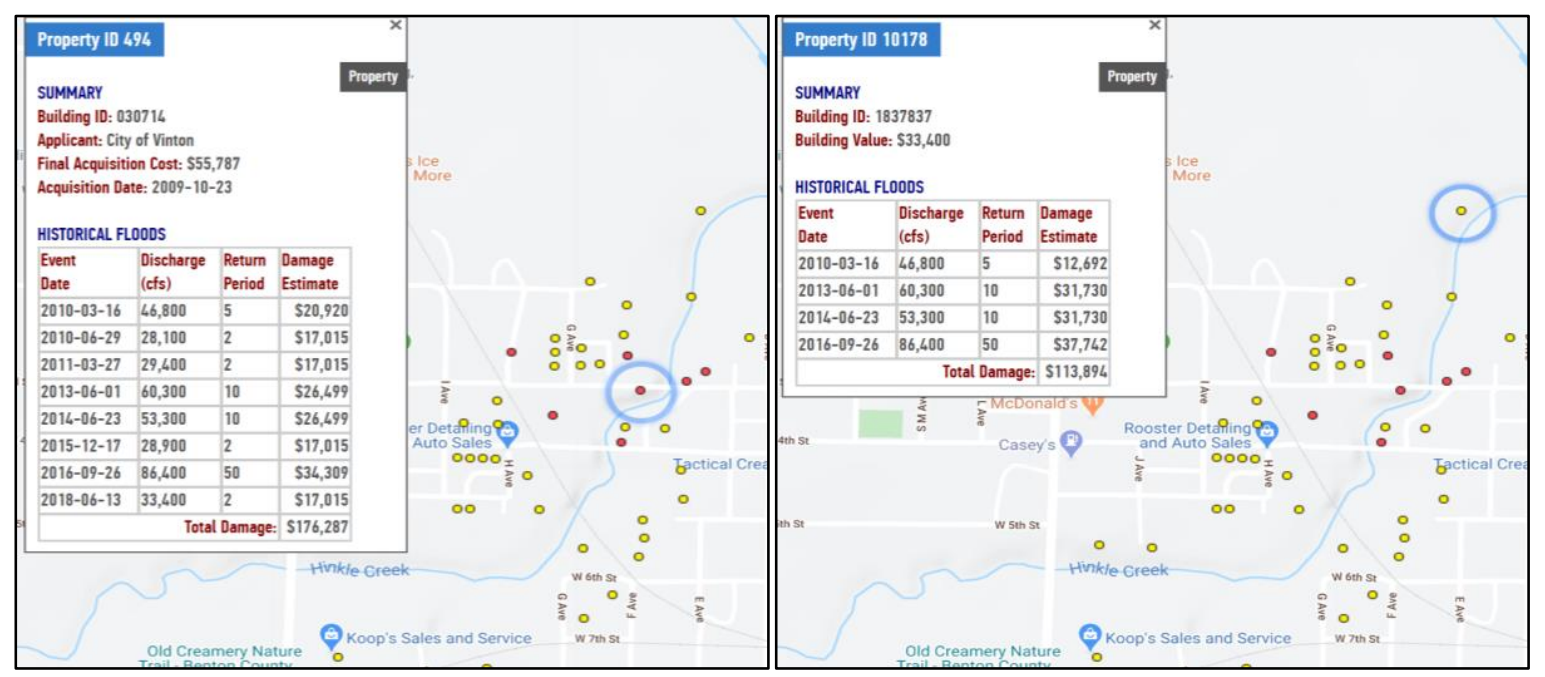

Figure 11. Avoided and historical flood losses for acquired (left) and existing (right) property respectively 
Summary of property acquisitions in the Middle Cedar watershed compared to disaster declarations and population are provided in Figure 12 Similar to Iowa level analysis, property buyouts are also not strongly correlated with the number of disaster declarations. However, the population is an indicator of the number of property buyouts in the Middle Cedar watershed.

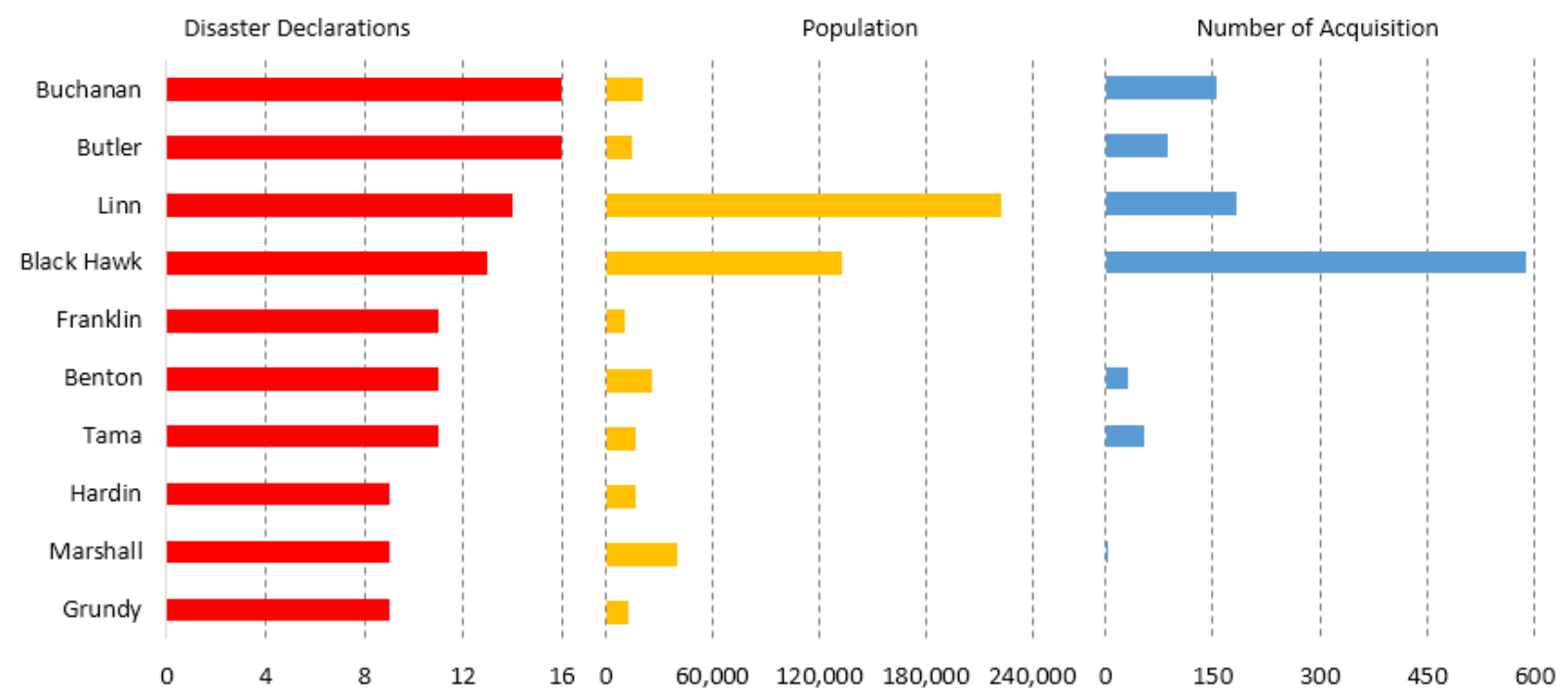

Figure 12. Comparison Between Property Acquisitions and Population/Disaster Declarations

\section{Conclusion}

This study presents a web-based data analytics framework for historical mitigation projects and property acquisitions for the State of Iowa. A case study is carried out to investigate the benefitcost analysis of historical buyouts and potential property acquisitions for existing properties based on climate scenarios in the future. The framework provides results in multiple scopes such as data source, program type, location, time, and multiple occupancies. Unlike GIS and desktop level applications, web systems allow non-technical users to exploring the comprehensive mitigation analysis results and generate customized reports with limited technical knowledge. This allows improving daily workflow for decision-makers and state agencies to analyze the vast amount of data at various geospatial and temporal scales using a friendly web interface. Therefore, a betterinformed decision for future mitigation efforts can be made by examining large scale datasets.

The case study reveals that the majority of the property buyouts are successful between the year of the acquisitions and today. The projected streamflow data is also a strong indicator of the success of property buyouts by avoiding significant damage in the future. It is important to emphasize that the case study is considered direct flood losses for structural and content damages. On the other hand, many indirect losses are hard to quantify but cannot be ignored. These indirect losses would increase the current BCAs, therefore the success of the buyouts. As new methodologies are introduced to quantify indirect losses, they can be integrated into existing BCA to enhance estimations in the framework. 


\section{References}

Agliamzanov, R., Sit, M. and Demir, I., 2020. Hydrology@ Home: a distributed volunteer computing framework for hydrological research and applications. Journal of Hydroinformatics, 22(2), pp.235-248.

Andjelkovic, I. (2001). Guidelines on non-structural measures in urban flood management. International Hydrological Programme (IHP), United Nations Educational, Scientific and Cultural Organization (UNESCO).

André, C., Monfort, D., Bouzit, M., \& Vinchon, C. (2013). Contribution of insurance data to cost assessment of coastal flood damage to residential buildings: insights gained from Johanna (2008) and Xynthia (2010) storm events. Natural Hazards and Earth System Sciences, 13(8), 2003-2012.

Boyle, K. J., \& Bergstrom, J. C. (1992). Benefit transfer studies: myths, pragmatism, and idealism. Water Resources Research, 28(3), 657-663.

Carson, A., Windsor, M., Hill, H., Haigh, T., Wall, N., Smith, J., Olsen, R., Bathke, D., Demir, I. and Muste, M., 2018. Serious gaming for participatory planning of multi-hazard mitigation. International journal of river basin management, 16(3), pp.379-391.

Demir, I. and Beck, M.B., 2009, April. GWIS: a prototype information system for Georgia watersheds. In Georgia Water Resources Conference: Regional Water Management Opportunities, UGA, Athens, GA, US.

Demir, I. and Szczepanek, R., 2017. Optimization of river network representation data models for web-based systems. Earth and Space Science, 4(6), pp.336-347.

Demir, I., Yildirim, E., Sermet, Y., \& Sit, M. A. (2018). FLOODSS: Iowa flood information system as a generalized flood cyberinfrastructure. International journal of river basin management, 16(3), 393-400.

Desvousges, W. H., Naughton, M. C., \& Parsons, G. R. (1992). Benefit transfer: conceptual problems in estimating water quality benefits using existing studies. Water resources research, 28(3), 675-683.

Downton, M. W., \& Pielke Jr, R. A. (2001). Discretion without accountability: Politics, flood damage, and climate. Natural Hazards Review, 2(4), 157-166.

Egli, T. (2002). Non-structural flood plain management: measures and their effectiveness. International Commission for the Protection of the Rhine (ICPR).

Federal Emergency Management Agency (FEMA) Website. Retrieved online Available online: https://www.fema.gov/data-visualization-summary-disaster-declarations-and-grants (accessed February 15, 2020)

Federal Emergency Management Agency (FEMA). Hazard Mitigation Grant Program. Available online: http://www.fema.gov/hazard-mitigation-grant-program (accessed 2020)

Federal Emergency Management Agency (FEMA). Robert T. Stafford Disaster Relief and Emergency Assistance Act, as Amended; FEMA: Washington, DC, USA, 2013. 
Gilles, D., Young, N., Schroeder, H., Piotrowski, J., \& Chang, Y. J. (2012). Inundation mapping initiatives of the Iowa Flood Center: Statewide coverage and detailed urban flooding analysis. Water, 4(1), 85-106.

Highfield, W. E., \& Brody, S. D. (2012). Evaluating the effectiveness of local mitigation activities in reducing flood losses. Natural Hazards Review, 14(4), 229-236.

IPCC, W. (2000). Special report on emissions scenarios. Intergovernmental panel on climate change special reports on climate change. Cambridge University Press, Cambridge, 570.

Knobloch, D. M. (2005). Moving a community in the aftermath of the great 1993 Midwest flood. Journal of Contemporary Water Research \& Education, 130(1), 41-45.

Kreibich, H., Thieken, A. H., Petrow, T., Müller, M., \& Merz, B. (2005). Flood loss reduction of private households due to building precautionary measures--lessons learned from the Elbe flood in August 2002. Natural Hazards and Earth System Science, 5(1), 117-126.

Mallakpour, I., \& Villarini, G. (2015). The changing nature of flooding across the central United States. Nature Climate Change, 5(3), 250.

Maly, E., \& Ishikawa, E. (2013). Land acquisition and buyouts as disaster mitigation after Hurricane Sandy in the United States. In Proceedings of international symposium on City Planning.

Marino, E. (2018). Adaptation privilege and Voluntary Buyouts: Perspectives on ethnocentrism in sea level rise relocation and retreat policies in the US. Global Environmental Change, 49, $10-13$.

Meunier, B., \& Merwade, V. (2014). Prioritizing levee repairs: a case study for the city of Indianapolis, Indiana. Natural hazards, 72(2), 997-1019.

Merz, B., Kreibich, H., Schwarze, R., \& Thieken, A. (2010). Review article" Assessment of economic flood damage". Natural Hazards and Earth System Sciences, 10(8), 1697-1724.

Merz, B., Thieken, A., \& Kreibich, H. (2011). Quantification of socio-economic flood risks. In Flood Risk Assessment and Management (pp. 229-247). Springer, Dordrecht.

Moel, H., Jongman, B., Kreibich, H., Merz, B., Penning-Rowsell, E., \& Ward, P. J. (2015). Flood risk assessments at different spatial scales. Mitigation and Adaptation Strategies for Global Change, 20(6), 865-890.

Quintero, F., Mantilla, R., Anderson, C., Claman, D., \& Krajewski, W. (2018). Assessment of changes in flood frequency due to the effects of climate change: Implications for engineering design. Hydrology, 5(1), 19.

Remo, J. W., Carlson, M., \& Pinter, N. (2012). Hydraulic and flood-loss modeling of levee, floodplain, and river management strategies, Middle Mississippi River, USA. Natural hazards, 61(2), 551-575.

Ready, R., \& Navrud, S. (2006). International benefit transfer: Methods and validity tests. Ecological economics, 60(2), 429-434.

Roy, E., Rousselle, J., \& Lacroix, J. (2003). Flood damage reduction Program (FDRP) in Quebec: Case study of the Chaudiere River. Natural Hazards, 28(2-3), 387-405. 
Scawthorn, C., Flores, P., Blais, N., Seligson, H., Tate, E., Chang, S., ... \& Lawrence, M. (2006). HAZUS-MH flood loss estimation methodology. II. Damage and loss assessment. Natural Hazards Review, 7(2), 72-81.

Sermet, Y. and Demir, I., 2019a. Flood action VR: a virtual reality framework for disaster awareness and emergency response training. In ACM SIGGRAPH 2019 Posters (pp. 1-2).

Sermet, Y. and Demir, I., 2019b. Towards an information centric flood ontology for information management and communication. Earth Science Informatics, 12(4), pp.541-551.

Sermet, Y., Demir, I. and Muste, M., 2020. A serious gaming framework for decision support on hydrological hazards. Science of The Total Environment, p.138895.

Sermet, Y., Villanueva, P., Sit, M.A. and Demir, I., 2020. Crowdsourced approaches for stage measurements at ungauged locations using smartphones. Hydrological Sciences Journal, 65(5), pp.813-822.

Sieg, T., Schinko, T., Vogel, K., Mechler, R., Merz, B., \& Kreibich, H. (2019). Integrated assessment of short-term direct and indirect economic flood impacts including uncertainty quantification. PloS one, 14(4), e0212932.

Sit, M. and Demir, I., 2019. Decentralized flood forecasting using deep neural networks. arXiv preprint arXiv:1902.02308.

Sit, M., Sermet, Y. and Demir, I., 2019. Optimized watershed delineation library for server-side and client-side web applications. Open Geospatial Data, Software and Standards, 4(1), p.8.

Thampapillai, D. J., \& Musgrave, W. F. (1985). Flood damage mitigation: A review of structural and nonstructural measures and alternative decision frameworks. Water Resources Research, 21(4), 411-424.

Wang, D., \& Hejazi, M. (2011). Quantifying the relative contribution of the climate and direct human impacts on mean annual streamflow in the contiguous United States. Water Resources Research, 47(10).

Weber, L.J., Muste, M., Bradley, A.A., Amado, A.A., Demir, I., Drake, C.W., Krajewski, W.F., Loeser, T.J., Politano, M.S., Shea, B.R. and Thomas, N.W., 2018. The Iowa Watersheds Project: Iowa's prototype for engaging communities and professionals in watershed hazard mitigation. International journal of river basin management, 16(3), pp.315-328.

White, E. (2011). Establishing long-term cost effectiveness of fema buyouts: a loss avoidance study of the acquisition/demolition of 22 properties in Shepherdsville, Kentucky.

Wuebbles, D. J., \& Hayhoe, K. (2004). Climate change projections for the United States Midwest. Mitigation and Adaptation Strategies for Global Change, 9(4), 335-363.

Xiang, Z., Yan, J. and Demir, I., 2020. A rainfall-runoff model with LSTM-based sequence-tosequence learning. Water resources research, 56(1), p.e2019WR025326.

$\mathrm{Xu}, \mathrm{H}$., Windsor, M., Muste, M. and Demir, I., 2020. A web-based decision support system for collaborative mitigation of multiple water-related hazards using serious gaming. Journal of Environmental Management, 255, p.109887.

Yildirim, E., (2017). Hazus-MH flood loss estimation on a Web-based system. Master's Thesis. University of Iowa. 
Yildirim, E., \& Demir, I. (2019). An integrated web framework for HAZUS-MH flood loss estimation analysis. Natural Hazards, 99(1), 275-286.

Zavar, E., \& Hagelman III, R. R. (2016). Land use change on US floodplain buyout sites, 19902000. Disaster Prevention and Management, 25(3), 360-374.

Zavar, E. An analysis of floodplain buyout memorials: four examples from central US floods of 1993-1998. GeoJournal, 1-12. 